Andrews University

Digital Commons @ Andrews University

Faculty Publications

$1-1-2005$

\title{
Habitat Patch Occupancy Dynamics of Glaucous-winged Gulls (larus glaucescens) ii: A Continuous-time Model
}

Smruti P. Damania

Andrews University, damania@andrews.edu

Karl W. Phillips

Andrews University

Shandelle M. Henson

Andrews University, henson@andrews.edu

James L. Hayward

Andrews University, hayward@andrews.edu

Follow this and additional works at: https://digitalcommons.andrews.edu/pubs

Part of the Ornithology Commons

\section{Recommended Citation}

Damania, Smruti P.; Phillips, Karl W.; Henson, Shandelle M.; and Hayward, James L., "Habitat Patch Occupancy Dynamics of Glaucous-winged Gulls (larus glaucescens) ii: A Continuous-time Model" (2005). Faculty Publications. 2158.

https://digitalcommons.andrews.edu/pubs/2158

This Article is brought to you for free and open access by Digital Commons @ Andrews University. It has been accepted for inclusion in Faculty Publications by an authorized administrator of Digital Commons @ Andrews University. For more information, please contact repository@andrews.edu. 


\title{
HABITAT PATCH OCCUPANCY DYNAMICS OF GLAUCOUS-WINGED GULLS (LARUS GLAUCESCENS) II: A CONTINUOUS-TIME MODEL
}

\author{
SMRUTI P. DAMANIA \\ Department of Biology \\ Andrews University \\ Berrien Springs, MI 49104 \\ KARL W. PHILLIPS \\ Department of Biology \\ Andrews University \\ Berrien Springs, MI 49104 \\ SHANDELLE M. HENSON \\ Department of Mathematics \\ Andrews University \\ Berrien Springs, MI 49104 \\ E-mail address: henson@andrews.edu
}

JAMES L. HAYWARD

Department of Biology

Andrews University

Berrien Springs, MI 49104

\begin{abstract}
The diurnal distribution and abundance dynamics of loafing Glaucous-winged Gulls (Larus glaucescens) were examined at Protection Island National Wildlife Refuge, Strait of Juan de Fuca, Washington. Asynchronous movement of gulls among three habitat patches dedicated to loafing was modeled as a function of environmental variables using differential equations. Multiple time scale analysis led to the derivation of algebraic models for habitat patch occupancy dynamics. The models were parameterized with hourly census data collected from each habitat patch, and the resulting model predictions were compared with observed census data. A four-compartment model explained $41 \%$ of the variability in the data. Models that predict the dynamics of organism distribution and abundance enhance understanding of the temporal and spatial organization of ecological systems, as well as the decision-making process in natural resource management.
\end{abstract}

KEY WORDS: Larus glaucescens, habitat patch dynamics, diurnal distribution, environmental factors, differential equation model.

1. Introduction. A major concern of ecology is the interaction between organisms and their environment, and how this interaction

Copyright (C)2005 Rocky Mountain Mathematics Consortium 
influences the temporal and spatial distribution of organisms. In addition to intra- and inter-specific factors, abiotic components of the environment can play crucial roles in determining distribution and abundance. Marine animals in particular rely heavily on environmental cues as they move from habitat to habitat to meet their functional needs. Time of day, tide height, solar elevation, and current velocity all play important roles in this regard (Henson et al. [2004], Hayward et al. [2005]). An understanding of these roles is useful to biologists involved in everything from the management of wildlife populations to the control of vector-borne diseases.

Theoretically, deterministic mechanisms that cause fluctuations in animal numbers can be expressed as mathematical equations capable of predicting census dynamics. Mathematical models have been used to predict the dynamics of laboratory systems such as flour beetle (Tribolium castaneum) and mite (Sancassania berlesei) populations, as well as aquatic microbial communities of rotifers (Brachiomus spp.; see, for example, Costantino et al. [1995, 1997], Fussmann et al. [2000], Bjørnstad and Grenfell [2001], Henson et al. [2001], Dennis et al. [2001], Benton et al. [2002]). Few mathematical models, however, have been linked rigorously to field data, whether for population dynamics or diurnal movement dynamics. Indeed, the multiple temporal and spatial scales and complexities of ecological interactions in the field make many ecologists skeptical that such models are possible.

Phillips et al. [2005] studied the diurnal habitat occupancy dynamics of Glaucous-winged Gulls (Larus glaucescens) at Protection Island National Wildlife Refuge, Washington. By collecting data on rates of gull movement among six designated habitat patches on the southeastern spit of Protection Island, and by estimating probabilities of transition between these habitats, they derived a discrete-time matrix model. The probabilities of transition between habitats were estimated as functions of two environmental variables, tide height and time of day. The habitat occupancy predictions generated by the model were compared with hourly census data using $R^{2}$ goodness-of-fit (Dennis et al. [2001]). While the model worked reasonably well for two of the terrestrial habitats, it could not predict the occupancy dynamics of the aquatic habitats. Observations suggested that the dynamics in the aquatic habitats were related not only to tide height and time of day, 
but also to ambient temperature, which was not considered in their model.

In this paper continuous-time models are used to revisit the system of habitat patches on Protection Island. In particular, this study focuses on the variations in numbers of gulls present in the three habitats identified by Phillips et al. [2005] which are dedicated to "loafing" behaviors (sleeping, resting, and preening). The remaining habitats are lumped into an "Other" category. Movement among the three loafing habitats (the pier, the marina and the beach) is modeled using differential equations that express flows between habitats as functions of four environmental variables: tide height, time of day, solar elevation, and temperature. A strong association between temperature and the number of gulls present on the aquatic loafing habitat is shown. Parameter estimations for the models in this paper are made indirectly from census data rather than directly from the flow rate data as in Phillips et al. [2005]. Two questions are addressed: What environmental factors influence gull movement among habitats? Is it possible to predict diurnal abundance patterns in multiple habitats solely on the basis of these environmental factors?

2. Modeling strategy. A single habitat may be viewed as a twocompartment system consisting of the habitat as one compartment and all other locations as the other. Occupancy dynamics within the habitat can then be modeled as

$$
\begin{aligned}
\frac{d x}{d t} & =\text { inflow rate }- \text { outflow rate } \\
& =r_{12}(K-x(t))-r_{21} x(t)
\end{aligned}
$$

where $x(t)$ is the number of birds in the censused habitat at time $t, K$ is the total number of birds in the system, $K-x(t)$ is the number of birds in the "Other" habitat, i.e., not in the censused habitat, $r_{12}$ is the per capita flow rate from Other to the censused habitat, and $r_{21}$ is the per capita flow rate from the censused habitat to Other.

Two-compartment models have been used to study the movement of waterfowl between habitat patches (Silverman and Kot [2000], Silverman et al. [2001]), the dynamics of loafing gulls on a pier (Henson et al. [2004]) and the haul-out dynamics of harbor seals (Hayward et al. 
[2005]). In the latter two studies, both carried out at Protection Island, Washington, per capita flow rates for animals moving into and out of habitats were found to be functions of deterministic exogenous factors such as tide height, current speed, and solar elevation. Expressing the per capita flow rates $r_{12}$ and $r_{21}$ as functions of the appropriate environmental variables gave rise to non-autonomous differential equation models for the occupancy dynamics of the habitat. Any remaining habitat structure of the system was folded into the "Other" category, possibly confounding environmental factors that influenced movement to and from the modeled habitat. Despite this limitation, two-compartment models can lead to a general understanding of how animals utilize particular habitats.

In this study a sequence of compartmental models is constructed to examine the dynamics of a system of three loafing habitats around the Protection Island gull colony. Two-compartment models are developed for each single habitat. On the basis of these simplified models, threecompartment models are constructed for each pair of habitats. Finally, a four-compartment model is developed for the system of three habitats. The final model arising from this step-wise approach explained a sizable portion of the variability in habitat occupancy data. The structure of the model offers insight into how gulls utilize each habitat in relation to the other habitats.

3. Study area. The study was carried out at Protection Island National Wildlife Refuge $\left(48^{\circ} 08^{\prime} \mathrm{N}, 122^{\circ} 55^{\prime} \mathrm{W}\right)$, Jefferson County, Washington, which contains one of the largest marine bird breeding colonies in the Pacific Northwest. The island is located $3.2 \mathrm{~km}$ from the mouth of Port Discovery Bay at the southeastern end of the Strait of Juan de Fuca, measures $2.9 \mathrm{~km} \times 0.9 \mathrm{~km}$ at its widest points, and consists mostly of a high plateau bordered by steep bluffs. Two gravel spits extend from the southeastern and southwestern ends of the island. This study focused on the southeastern spit, Violet Point, which measures $800 \times 200 \mathrm{~m}$ and supports more than 2400 pairs of nesting gulls (J. Galusha [pers. comm.]). Three distinct loafing habitats on or around Violet Point were chosen for study. Behavior designations follow Phillips [2004]. 
1. Pier: This structure consists of wood pilings, concrete pier, metal gangplank and railings that extend into a small marina. One to three boats were usually moored to this structure, but birds on the boats were not counted as being in this habitat. The primary gull behaviors observed here included resting, preening, and sleeping.

2. Marina: This small body of water is located toward the southwest end of Violet Point and surrounds the pier. The marina is accessible by boat through an artificial inlet on the south side of Violet Point. It is closed to the public and experiences little human disturbance. Behaviors observed in this habitat included drinking, bathing, preening, and floating.

3. Beach: This habitat included the north and south beaches of Violet Point. A 113-m stretch along the north beach was used as a sample area for censuses. Behaviors observed in this habitat included resting, preening, and sleeping. Phillips et al. [2005] determined that the ratio of the number of gulls using the sample area to the number using the entire beach was $1 / 5.13$. Thus, sample observations were multiplied by 5.13 to give an estimate of the total number of gulls on the entire beach.

All other areas were placed in the "Other" category.

4. Data collection. From 24 June to 10 July, in 2002 and 2003, hourly counts of the numbers of Glaucous-winged Gulls present in each of the three study habitats were collected. Data were collected at the top of each hour from 0600-2000 PST (Pacific Standard Time), for at least three days per week. Observations were made using a $20-60 \mathrm{x}$ spotting scope and 10x binoculars from an observation point atop a 33$\mathrm{m}$ bluff overlooking Violet Point. The observation point was at least $100 \mathrm{~m}$ from the closest habitat (the Pier and the proximal edge of the colony); the presence of observers did not appear to affect the system in any way. Occupancy counts that occurred within 30 min after a disturbance, for example when the dock was cleaned or when Bald Eagles (Haliaeetus leucocephalus) flew over, were eliminated. Some occupancy counts were missed due to dense fog.

Four environmental variables, three available as long-range predictions and one available only as a short-range prediction, were considered in the analysis: tide height (tide), solar elevation (sun), time of day PST 
(hour), and temperature (temp). Hourly tidal and solar elevation data were downloaded from the National Oceanic and Atmospheric Administration (NOAA) websites http://co-ops.nos.noaa.gov/data_retrieve. shtml?input_code $=100111111 \mathrm{vwl}$ and http://www.srrb.noaa.gov/highlights/sunrise/azel.html. Historical tidal data were obtained for the Port Townsend station, Admiralty Inlet, Washington, and were multiplied by a correction factor of 0.93 for Protection Island (Anonymous [1998]). Hourly historical temperature data were obtained from the University of Washington website http://www-k12.atmos.washington. $\mathrm{edu} / \mathrm{k} 12 /$ grayskies/nw_weather.html. Each of the four environmental variables was non-dimensionalized and normalized so that

$$
1 \leq \text { tide, sun, temp, hour } \leq 2 .
$$

\section{Modeling assumptions.}

(A1) The total number $K$ of gulls in the system, although seasonally variable, was assumed to remain constant over the data collection period. The value of $K$ was estimated as follows. During the summers of both 2002 and 2003, Phillips [2004] collected occupancy data in sample areas of two additional habitats, Colony and Water. The assumption was made that all birds in remote feeding locations had returned to the habitats surrounding the colony by dusk. Thus, $K$ was taken to be

$$
\begin{aligned}
K & =\max _{\text {time } t}\left[\text { Pier }+ \text { Marina }+s_{B} * \text { Beach }+s_{c} * \text { Colony }+s_{w} * \text { Water }\right] \\
& =6492 \text { (occurring at } 2000 \text { hours PST on } 28 \text { June 2002) }
\end{aligned}
$$

where $s_{B}=5.13$ is the scaling factor for the Beach, and $s_{C}$ and $s_{W}$ represent the scaling factors for the Colony and the Water, as computed in Phillips [2004].

(A2) The per capita flow rates $r_{i j}$ from habitat $j$ to habitat $i$ were assumed to be proportional to functions of environmental factors: $r_{i j}=\alpha_{i j} E_{i j}(t)$, where $\alpha_{i j}>0$ is a constant of proportionality and $E_{i j}(t)=\operatorname{tide}^{a_{i j}} \operatorname{sun}^{b_{i j}}$ temp $^{c_{i j}}$ hour $^{d_{i j}}$ is a multiplicative function of powers of environmental variables. In particular, the per capita flow 
rates were assumed to be density independent. The procedures for determining the environmental variables and their exponents, and for estimating the parameters $\alpha_{i j}$, are given in Sections 9 and 10.

(A3) The flow rates between the Pier and Beach, and from the Beach to the Marina, were assumed to be zero. Flow from Other to the Pier in the three- and four-compartment models was also assumed to be zero. These assumptions were based on flow rate observations collected by Phillips [2004]. Per capita flow rates were noted to be particularly small in the above-mentioned instances, and thus were eliminated to reduce the total number of parameters in the models.

(A4) The system was assumed to recover rapidly after disturbance. In particular, it was assumed that after a perturbation, all habitat occupancies changed much faster than the environmental variables, so that the environmental conditions could be considered constant during recovery. This assumption was suggested by the results of Henson et al. [2004], as well as by seven years of extensive observations, during which time it has become clear that the habitat occupancies recover within approximately 20 minutes after most disturbances.

(A5) The main source of noise in the census data was assumed to be demographic stochasticity, due to a stochastic "arrival-and-departure" process (Hayward et al. [2005]), rather than environmental stochasticity. This assumption was motivated by three considerations. First, a post hoc inspection of model residuals showed that the variance of the residual model errors was stabilized by a square root transformation (Rao [1973], Dennis et al. [2001], Hayward et al. [2005]). Second, all major environmental correlates were incorporated explicitly into the models. Third, data collected within 30 minutes after a disturbance (such as an eagle flyover or person walking onto the pier) were eliminated from the data set.

(A6) The hourly residual model errors were assumed to be uncorrelated in time. That is, it was assumed that a stochastic event affecting the census at one hour would not affect the census an hour later, due to the rapid recovery of the system post-perturbation, assumption (A4). Furthermore, at any given census time $t$ the covariances of the residuals between habitats were assumed small relative to the variances. That is, it was assumed that stochastic events mainly affected single habitats. 
6. Two-compartment models. Three two-compartment models of the form

$$
\frac{d x}{d t}=r_{12}(K-x)-r_{21} x
$$

were constructed, one for each of the Pier, Marina and Beach. Here $x$ is the number of birds in the censused habitat, $K$ is the total number of birds in the system, $K-x$ is the number of birds in Other, i.e., not in the censused habitat, $r_{12}$ is the per capita flow rate from Other to the censused habitat and $r_{21}$ is the per capita flow rate from the censused habitat to Other.

Using assumption A4 and multiple time scale analysis, the steady state dynamics of the differential equation (1) can be approximated by the algebraic equation

$$
x(t)=\frac{K}{1+\left(r_{21}(t) / r_{12}(t)\right)}
$$

(Hoppensteadt [1975], Tikhonov et al. [1985], Hayward et al. [2005], Henson et al. [2005]). Since $r_{21}=\alpha_{21} E_{21}$ and $r_{12}=\alpha_{12} E_{12}$, the steady state equation (2) can be written as

$$
x(t)=\frac{K}{1+\left(\alpha_{21} E_{21}(t)\right) /\left(\alpha_{12} E_{12}(t)\right)} .
$$

Two important comments are in order. First, the "inverse problem" is not well defined, since the steady state model depends on the ratio of the two environmental functions $E_{21}$ and $E_{12}$, and on the ratio of their associated parameters $\alpha_{21}$ and $\alpha_{12}$. Infinitely many combinations of environmental functions and parameters will give the same ratio, and hence the same model output. Thus, using only census data from steady state dynamics, one cannot determine with certainty the identity of the environmental functions $E_{i j}$ that determine flow rates between habitats. Furthermore, model fitting will not yield a unique set of parameters. In the two-compartment model, the ratio of the two parameters can be replaced by a single parameter. In higherdimensional models, however, it is not so obvious how to eliminate parameters. In order for the inverse problem to be well defined, one must have data collected at small time intervals immediately after 
a disturbance, as well as steady state data (Hayward et al. [2005], Henson et al. [2005]). Second, model (2) could be constructed as a simple relationship between $x$ and the environmental functions without reference to a differential equation: $x$ increases when $E_{21}$ decreases or $E_{12}$ increases. In the higher-dimensional models below, the steady state equations are not so simple and would be difficult to derive directly without reference to compartment models.

Noise is ubiquitous in ecological systems. In order to link model (2) to data, one must first model the departure of the data from the model predictions. Under assumption (A5), the noise is approximately additive on the square root scale (Rao [1973], Dennis et al. [2001], Hayward et al. [2005]):

$$
\sqrt{x(t)}=\sqrt{\frac{K}{1+\left(r_{21}(t) / r_{12}(t)\right)}}+\sigma \varepsilon(t),
$$

where the $\varepsilon(t)$ are standard normal random variables (mean zero and standard deviation one) uncorrelated in time, assumption (A6), and $\sigma$ is a positive constant. The normal random variable $\sigma \varepsilon(t)$ has mean zero and standard deviation $\sigma$ and represents the departure of data observations from model predictions. That is, the residuals

$$
\rho_{t}=\sqrt{\text { observation }_{t}}-\sqrt{\text { prediction }_{t}}
$$

are distributed as $\sigma \varepsilon(t)$.

Thus, the stochastic version of model (2) may be written as

$$
x(t)=\left(\sqrt{\frac{K}{1+\left(r_{21}(t) / r_{12}(t)\right)}}+\sigma \varepsilon(t)\right)^{2} .
$$

7. Three-compartment models. Two three-compartment models of the form

$$
\begin{aligned}
& \frac{d x_{1}}{d t}=r_{12} x_{2}+r_{13}\left(K-x_{1}-x_{2}\right)-r_{21} x_{1}-r_{31} x_{1} \\
& \frac{d x_{2}}{d t}=r_{21} x_{1}+r_{23}\left(K-x_{1}-x_{2}\right)-r_{12} x_{2}-r_{32} x_{2}
\end{aligned}
$$


were constructed for the Pier/Marina system and the Marina/Beach system. Due to negligible flow between the Pier and the Beach, the Pier/Beach system was not modeled. Here $x_{1}$ and $x_{2}$ are the occupancies of the censused habitats, $K$ is the total number of birds in the system, and $K-x_{1}-x_{2}$ is the occupancy of Other. The four positive terms indicate inflow rates into the censused habitats, while the four negative terms indicate outflow rates.

In this case, multiple time scale analysis yields the algebraic steady state model

$$
x_{1}(t)=\frac{\operatorname{det} A_{1}(t)}{\operatorname{det} A(t)} K, \quad x_{2}(t)=\frac{\operatorname{det} A_{2}(t)}{\operatorname{det} A(t)} K,
$$

where

$$
\begin{aligned}
A & =\left(\begin{array}{cc}
-r_{13}-r_{21}-r_{31} & r_{12}-r_{13} \\
r_{21}-r_{23} & -r_{23}-r_{12}-r_{32}
\end{array}\right), \\
A_{1} & =\left(\begin{array}{cc}
-r_{13} & r_{12}-r_{13} \\
-r_{23} & -r_{23}-r_{12}-r_{32}
\end{array}\right), \\
A_{2} & =\left(\begin{array}{cc}
-r_{13}-r_{21}-r_{31} & -r_{13} \\
r_{21}-r_{23} & -r_{23}
\end{array}\right)
\end{aligned}
$$

(Henson et al. [2005]). Expansion of the determinants in (3) yields the model equations

$$
\begin{aligned}
& x_{1}= \frac{K}{1+\frac{\left(r_{21} r_{13}+r_{21} r_{23}+r_{31} r_{23}\right)+\left(r_{12} r_{31}+r_{21} r_{32}+r_{31} r_{32}\right)}{\left(r_{12} r_{13}+r_{12} r_{23}+r_{31} r_{32}\right)}}, \\
& x_{2}=\frac{K}{1+\frac{\left(r_{12} r_{13}+r_{12} r_{23}+r_{13} r_{32}\right)+\left(r_{12} r_{31}+r_{21} r_{32}+r_{31} r_{32}\right)}{\left(r_{21} r_{13}+r_{21} r_{23}+r_{31} r_{23}\right)}} .
\end{aligned}
$$

Note that these equations, although algebraic, are quite complicated and would be difficult to derive directly without the differential equation model. 
The stochastic version of the three-compartment model was taken to be

$$
\begin{aligned}
& x_{1}(t)=\left(\sqrt{\frac{\operatorname{det} A_{1}(t)}{\operatorname{det} A(t)} K}+\sigma_{1} \varepsilon_{1}(t)\right)^{2}, \\
& x_{2}(t)=\left(\sqrt{\frac{\operatorname{det} A_{2}(t)}{\operatorname{det} A(t)} K}+\sigma_{2} \varepsilon_{2}(t)\right)^{2},
\end{aligned}
$$

where the $\varepsilon_{1}(t)$ and $\varepsilon_{2}(t)$ are standard normal random variables uncorrelated in time, assumption (A6), and $\sigma_{1}$ and $\sigma_{2}$ are positive constants. Since the same parameters $\alpha_{i j}$ appear in both equations, at any given hour $t$ the random variables $\varepsilon_{1}(t)$ and $\varepsilon_{2}(t)$ would in general be expected to covary. In this study, however, the covariances were assumed small relative to the variances and were taken to be zero, assumption (A6).

8. Four-compartment model. The system of three loafing habitats was modeled with a four-compartment model of the form

$$
\begin{aligned}
\frac{d x_{1}}{d t} & =r_{12} x_{2}+r_{13} x_{3}+r_{14}\left(K-x_{1}-x_{2}-x_{3}\right)-r_{21} x_{1}-r_{31} x_{1}-r_{41} x_{1} \\
\frac{d x_{2}}{d t} & =r_{21} x_{1}+r_{23} x_{3}+r_{24}\left(K-x_{1}-x_{2}-x_{3}\right)-r_{12} x_{2}-r_{32} x_{2}-r_{42} x_{2} \\
\frac{d x_{3}}{d t} & =r_{31} x_{1}+r_{32} x_{2}+r_{34}\left(K-x_{1}-x_{2}-x_{3}\right)-r_{13} x_{3}+r_{23} x_{3}+r_{43} x_{3} .
\end{aligned}
$$

Here $x_{1}, x_{2}$ and $x_{3}$ denote the number of birds utilizing the Pier, Marina, and Beach, respectively, at time $t, K$ is the total number of birds in the system, and $K-x_{1}-x_{2}-x_{3}$ is the occupancy of Other. The $r_{i j}$ denote per capita flow rates from habitat $j$ to habitat $i$. Based on assumption A3, the per capita flow rates $r_{14}, r_{23}, r_{13}$ and $r_{31}$ were taken to be zero, see Figure 1.

For the four-compartment model, the algebraic steady state model is (4)

$$
x_{1}(t)=\frac{\operatorname{det} A_{1}(t)}{\operatorname{det} A(t)} K, \quad x_{2}(t)=\frac{\operatorname{det} A_{2}(t)}{\operatorname{det} A(t)} K, \quad x_{3}(t)=\frac{\operatorname{det} A_{3}(t)}{\operatorname{det} A(t)} K,
$$




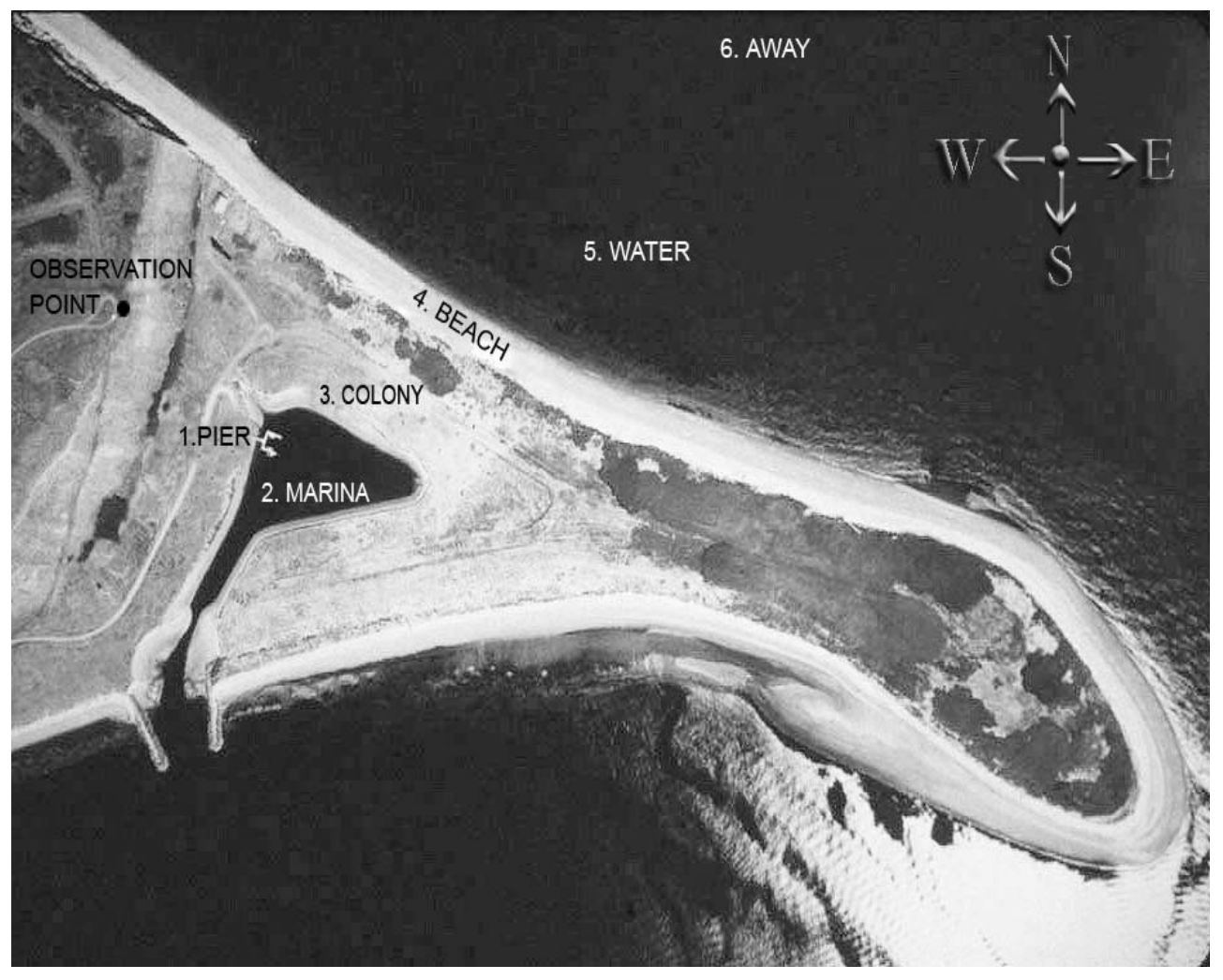

FIGURE 1. Aerial photograph of Violet Point, Protection Island, showing the locations of the six designated habitats including the three study loafing habitats in relation to the observation point. 
where

$$
\begin{aligned}
& \text { A } \\
& =\left(\begin{array}{ccc}
-r_{14}-r_{21}-r_{31}-r_{41} & r_{12}-r_{14} & r_{13}-r_{14} \\
r_{21}-r_{24} & -r_{24}-r_{12}-r_{32}-r_{42} & r_{23}-r_{24} \\
r_{31}-r_{34} & r_{32}-r_{34} & -r_{34}-r_{13}-r_{23}-r_{43}
\end{array}\right), \\
& A_{1}=\left(\begin{array}{ccc}
-r_{14} & r_{12}-r_{14} & r_{13}-r_{14} \\
-r_{24} & -r_{24}-r_{12}-r_{32}-r_{42} & r_{23}-r_{24} \\
-r_{34} & r_{32}-r_{34} & -r_{34}-r_{13}-r_{23}-r_{43}
\end{array}\right) \\
& A_{2}=\left(\begin{array}{ccc}
-r_{14}-r_{21}-r_{31}-r_{41} & -r_{14} & r_{13}-r_{14} \\
r_{21}-r_{24} & -r_{24} & r_{23}-r_{24} \\
r_{31}-r_{34} & -r_{34} & -r_{34}-r_{13}-r_{23}-r_{43}
\end{array}\right), \\
& A_{3}=\left(\begin{array}{ccc}
-r_{14}-r_{21}-r_{31}-r_{41} & r_{12}-r_{14} & -r_{14} \\
r_{21}-r_{24} & -r_{24}-r_{12}-r_{32}-r_{42} & -r_{24} \\
r_{31}-r_{34} & r_{32}-r_{34} & -r_{34}
\end{array}\right)
\end{aligned}
$$

(Henson et al. [2005]). If the determinants in (4) were to be expanded, the resulting algebraic equations for the four-compartment steady state model would be found to be very complicated indeed, too complicated to fit on one line of this paper.

The stochastic version of the four-compartment model was taken to be

$$
\begin{aligned}
& x_{1}(t)=\left(\sqrt{\frac{\operatorname{det} A_{1}(t)}{\operatorname{det} A(t)} K}+\sigma_{1} \varepsilon_{1}(t)\right)^{2}, \\
& x_{2}(t)=\left(\sqrt{\frac{\operatorname{det} A_{2}(t)}{\operatorname{det} A(t)} K}+\sigma_{2} \varepsilon_{2}(t)\right)^{2}, \\
& x_{3}(t)=\left(\sqrt{\frac{\operatorname{det} A_{3}(t)}{\operatorname{det} A(t)} K}+\sigma_{3} \varepsilon_{3}(t)\right)^{2},
\end{aligned}
$$

where $\varepsilon_{1}(t), \varepsilon_{2}(t)$ and $\varepsilon_{3}(t)$ are standard normal random variables uncorrelated in time, and $\sigma_{1}, \sigma_{2}$ and $\sigma_{3}$ are positive constants. As before, for each hour $t$ the covariances of $\varepsilon_{1}(t), \varepsilon_{2}(t)$ and $\varepsilon_{3}(t)$ were assumed to be zero. 


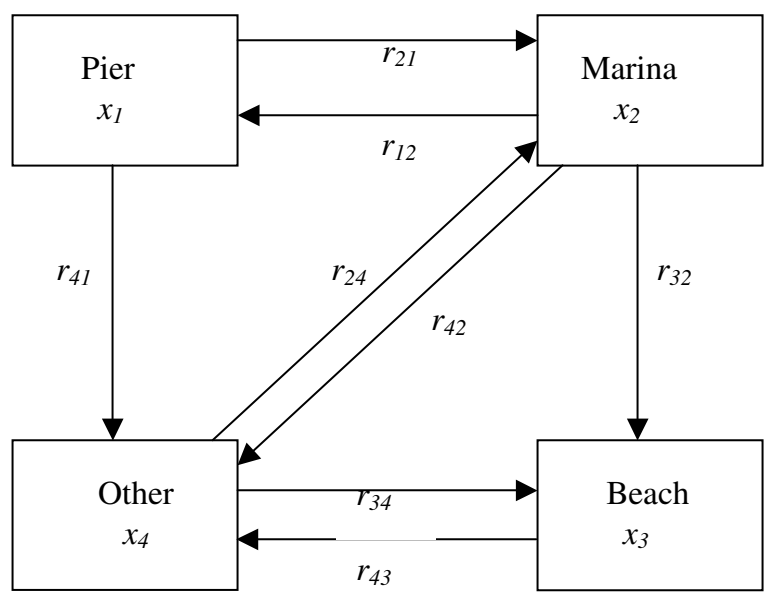

FIGURE 2. Glaucous-winged Gull movement patterns across different habitat patches on Protection Island in the four-compartment system.

9. Alternative models. In order to reduce the number of parameters so that numerical model fitting would remain tractable for the higher-dimensional models, the exponents in each $E_{i j}=$ tide $^{a_{i j}}$ sun $^{b_{i j}}$ temp $^{c_{i j}}$ hour $^{d_{i j}}$ were determined by methods of model selection rather than parameter estimation. For example, for each twocompartment model, an array of $2(3)^{4}=162$ alternative models was constructed by taking $a_{i j}, b_{i j}, c_{i j}, d_{i j} \in\{-1,0,1\}$ for $E_{12}$ and $E_{21}$. Following the procedure detailed in Hayward et al. [2005], a subset of these models was parameterized, that is, $\alpha_{12}$ and $\alpha_{21}$ were estimated numerically as in Section 10, and all but the best-fitting model were eliminated. The best-fitting model was then tested to determine whether higher integer exponents might increase its goodness-of-fit. In this way the best integer exponents were quickly determined "by hand." For the two-compartment models, the exponents were also estimated numerically as model parameters; allowing fractional exponents did not significantly increase model fit. For the three- and four-compartment models, it was not possible to estimate the exponents as model parameters, and all exponents were determined "by hand" through the model selection procedure. 
Determination of the best $E_{i j}$ for the two-compartment models greatly reduced the number of alternative three-compartment models. This, in turn, reduced of the number of alternative four-compartment models. The $E_{i j}$ that were found to give the best fit for each model are listed in Table 1.

10. Model parameterizations. The method of maximum likelihood (ML) was used to estimate the parameters $\alpha_{i j}$ from the hourly census data. Let $q$ be the number of observations for each habitat, $n$ be the number of censused habitats, and

$$
\rho_{t i}=\sqrt{\text { observation }_{t i}}-\sqrt{\text { prediction }_{t i}}
$$

be the residual error at time $t$ for the $i$ th habitat, computed on the square root scale. Let $\mathbf{y}_{t}=\left\langle\rho_{t 1}, \rho_{t 2}, \ldots, \rho_{t n}\right\rangle$ be the row vector of residuals for the $n$ habitats at time $t$, and let $\mathbf{y}_{t}^{\tau}$ be the column vector of residuals at time $t$.

The stochastic model structure (noise additive on the square root scale) assumes that the residuals $\mathbf{y}_{t}$ come from a multivariate normal distribution with mean zero and some variance-covariance matrix $\Sigma$. Thus, the likelihood that a given set of observations at time $t$, and hence a given residual vector $\mathbf{y}_{t}$, arose as a realization of the stochastic model is given by the multivariate normal probability density function (pdf)

$$
P\left(\mathbf{y}_{t}\right)=\left(\frac{1}{|\Sigma|^{1 / 2}(2 \pi)^{n / 2}}\right) \exp \left(-\frac{1}{2} \mathbf{y}_{t} \Sigma^{-1} \mathbf{y}_{t}^{\tau}\right)
$$

(Hogg and Craig [1978]). Under the assumption A6 that the residuals are independent in time, the likelihood that the entire time series of observations arose from the stochastic process described by the model is

$$
L(\Theta, \Sigma)=\prod_{t=1}^{q} P\left(\mathbf{y}_{t}\right)=\prod_{t=1}^{q}\left[\left(\frac{1}{|\Sigma|^{1 / 2}(2 \pi)^{n / 2}}\right) \exp \left(-\frac{1}{2} \mathbf{y}_{t} \Sigma^{-1} \mathbf{y}_{t}^{\tau}\right)\right]
$$

where $\Theta$ is the vector of model parameters.

The ML parameter estimates are those that maximize the likelihood function $L$, or, equivalently, the log-likelihood function

$$
\ln L(\Theta, \Sigma)=-\frac{n q}{2} \ln (2 \pi)-\frac{q}{2} \ln |\Sigma|-\frac{1}{2} \sum_{t=1}^{q} \mathbf{y}_{t} \Sigma^{-1} \mathbf{y}_{t}^{\tau} .
$$


TABLE 1. Best flow rate structures for each compartmental model along with corresponding $R^{2}$ values for habitat occupancies by Glaucous-winged Gulls on Protection Island. In each case, "Other" refers to all locations other than those being modeled. Note that $r_{i j}$ refers to the per capita flow rate from habitat $j$ to habitat $i$. Maximum likelihood (ML) parameter estimates are given for each model structure.

\begin{tabular}{|c|c|c|c|}
\hline & $r_{i j}$ & $\begin{array}{l}\text { ML parameter } \\
\text { estimates }\end{array}$ & $\overline{R^{2}}$ \\
\hline $\begin{array}{l}\text { Pier }(1) / \\
\text { Other }(2)\end{array}$ & $\begin{array}{l}r_{21}=\alpha_{21}(\text { sun }) /\left(\text { tide }^{*} \text { temp }\right) \\
r_{12}=\alpha_{12}\left(\text { tide* }^{*} \text { hour }\right) / \\
\text { (temp*sun) }\end{array}$ & $\begin{array}{l}\alpha_{21}=0.0007 \\
\alpha_{12}=405.94\end{array}$ & $R_{\text {Pier }}^{2}=0.76$ \\
\hline $\begin{array}{l}\text { Marina (1) / } \\
\text { Other (2) }\end{array}$ & $\begin{array}{l}r_{21}=\alpha_{21} 1 /\left(\text { temp }^{2}\right) \\
r_{12}=\alpha_{12} \text { hour* }^{*} \text { tide }^{*} \text { temp }^{3}\end{array}$ & $\begin{array}{l}\alpha_{21}=0.0090 \\
\alpha_{12}=57.677\end{array}$ & $R_{\text {Marina }}^{2}=0.43$ \\
\hline $\begin{array}{l}\text { Beach }(1) / \\
\text { Other }(2)\end{array}$ & $\begin{array}{l}r_{21}=\alpha_{21} 1 / \text { tide } \\
r_{12}=\alpha_{12} \text { hour }\end{array}$ & $\begin{array}{l}\alpha_{21}=0.2070 \\
\alpha_{12}=3.9285\end{array}$ & $R_{\text {Beach }}^{2}=0.34$ \\
\hline $\begin{array}{l}\text { Pier (1) / } \\
\text { Marina (2) / } \\
\text { Other (3) }\end{array}$ & $\begin{array}{l}r_{12}=\alpha_{12} \text { hour } / \text { temp }^{2} \\
r_{21}=\alpha_{21} \text { temp }^{3} \\
r_{13}=0 \\
r_{31}=\alpha_{31} \text { sun }^{3} / \text { tide }^{3} \\
r_{23}=\alpha_{23} \text { temp }^{2 *} \text { hour } \\
r_{32}=\alpha_{32} 1 /\left(\text { temp }^{2 *} \text { tide }\right)\end{array}$ & $\begin{aligned} \alpha_{12} & =11.01073 \\
\alpha_{21} & =0.96406 \\
\alpha_{31} & =1.58887 \\
\alpha_{23} & =0.00529 \\
\alpha_{32} & =14.8330\end{aligned}$ & $\begin{array}{l}R_{\text {Pier }}^{2}=0.76 \\
R_{\text {Marina }}^{2}=0.42 \\
R_{\text {Overall }}^{2}=0.64\end{array}$ \\
\hline $\begin{array}{l}\text { Marina (1)/ } \\
\text { Beach (2)/ } \\
\text { Other (3) }\end{array}$ & $\begin{array}{l}r_{21}=\alpha_{21} 1 /\left(\text { temp }^{2 *} \text { tide }\right) \\
r_{12}=0 \\
r_{31}=\alpha_{31} 1 /\left(\text { temp }^{2 *} \text { tide }\right) \\
r_{13}=\alpha_{13} \text { temp }{ }^{2 *} \text { hour } \\
r_{23}=\alpha_{23} \text { hour } \\
r_{32}=\alpha_{32} 1 / \text { tide }\end{array}$ & $\begin{aligned} \alpha_{21} & =8.70382 \\
\alpha_{31} & =22.19711 \\
\alpha_{13} & =0.00800 \\
\alpha_{23} & =0.01803 \\
\alpha_{32} & =0.42291\end{aligned}$ & $\begin{array}{l}R_{\text {Marina }}^{2}=0.41 \\
R_{\text {Beach }}^{2}=0.35 \\
R_{\text {Overall }}^{2}=0.35\end{array}$ \\
\hline $\begin{array}{l}\text { Pier (1) / } \\
\text { Marina (2) / } \\
\text { Beach (3) / } \\
\text { Other (4) }\end{array}$ & $\begin{array}{l}r_{12}=\alpha_{12} \text { hour } / \text { temp }^{2} \\
r_{21}=\alpha_{21} \text { temp }^{3} \\
r_{24}=\alpha_{24} \text { hour }^{*} \text { temp }^{3} \\
r_{32}=\alpha_{32} 1 /\left(\text { tide }^{*} \text { temp }\right) \\
r_{23}=0 \\
r_{34}=\alpha_{34} \text { hour } \\
r_{41}=\alpha_{41} \text { sun }^{3} / \text { tide }^{3} \\
r_{14}=0 \\
r_{42}=\alpha_{42} 1 /(\text { temp } \\
2 * \text { tide }) \\
r_{43}=\alpha_{43} 1 / \text { tide } \\
r_{13}=0 \\
r_{31}=0\end{array}$ & $\begin{array}{l}\alpha_{12}=41.8047 \\
\alpha_{21}=3.30940 \\
\alpha_{24}=0.01886 \\
\alpha_{32}=46.4665 \\
\alpha_{34}=0.26589 \\
\alpha_{41}=6.80682 \\
\alpha_{42}=2.55731 \mathrm{e}-05 \\
\alpha_{43}=5.59700\end{array}$ & $\begin{array}{l}R_{\text {Pier }}^{2}=0.76 \\
R_{\text {Marina }}^{2}=0.43 \\
R_{\text {Beach }}^{2}=0.35 \\
R_{\text {Overall }}^{2}=0.41\end{array}$ \\
\hline
\end{tabular}


Since the covariances were assumed small compared to the variances (assumption A6), the variance-covariance matrix is taken to be diagonal:

$$
\Sigma=\left(\begin{array}{ccc}
\sigma_{1}^{2} & & 0 \\
& \ddots & \\
0 & & \sigma_{n}^{2}
\end{array}\right) .
$$

Thus the inverse and determinant of $\Sigma$ are given by

$$
\Sigma^{-1}=\left(\begin{array}{ccc}
1 / \sigma_{1}^{2} & & 0 \\
& \ddots & \\
0 & & 1 / \sigma_{n}^{2}
\end{array}\right) \quad \text { and }|\Sigma|=\sigma_{1}^{2} \sigma_{2}^{2} \cdots \sigma_{n}^{2}
$$

Hence, the log-likelihood function can be written as

$$
\begin{aligned}
\ln L(\Theta, \Sigma) & =-\frac{n q}{2} \ln (2 \pi)-\frac{q}{2} \ln \left(\prod_{i=1}^{n} \sigma_{i}^{2}\right)-\frac{1}{2} \sum_{t=1}^{q} \sum_{i=1}^{n}\left(\frac{1}{\sigma_{i}^{2}} \rho_{t i}^{2}\right) \\
& =-\frac{n q}{2} \ln (2 \pi)-\frac{q}{2} \sum_{i=1}^{n} \ln \left(\sigma_{i}^{2}\right)-\frac{1}{2} \sum_{i=1}^{n} \frac{1}{\sigma_{i}^{2}} \sum_{t=1}^{q} \rho_{t i}^{2} .
\end{aligned}
$$

Differentiating $\ln L(\Theta, \Sigma)$ with respect to a given $\sigma_{j}$ and setting the partial derivative equal to zero yields an equation of the form

$$
\frac{\partial}{\partial \sigma_{j}} \ln L(\Theta, \Sigma)=-\frac{q}{\sigma_{j}}+\frac{1}{\sigma_{j}^{3}} \sum_{t=1}^{q} \rho_{t j}^{2}=0
$$

for each of $j=1,2, \ldots, n$. That is to say, at the maximizer, the estimated variances $\hat{\sigma}_{j}^{2}$ must be related to the fitted residuals $\hat{\rho}_{t j}^{2}$ as

$$
\hat{\sigma}_{j}^{2}=\frac{1}{q} \sum_{t=1}^{q} \hat{\rho}_{t j}^{2}
$$

Thus, the maximizer of the function $\ln L(\Theta, \Sigma)$ will also be the maximizer of the function obtained from $\ln L(\Theta, \Sigma)$ by replacing the $\sigma_{i}^{2}$ with 
$(1 / q) \sum_{t=1}^{q} \rho_{t i}^{2}:$

$$
\begin{aligned}
F(\Theta) & =-\frac{n q}{2} \ln (2 \pi)-\frac{q}{2} \ln \left(\prod_{i=1}^{n}\left[\frac{1}{q} \sum_{t=1}^{q} \rho_{t i}^{2}\right]\right)-\frac{n q}{2} \\
& =-\frac{n q}{2} \ln (2 \pi)-\frac{q}{2} \ln \left(\frac{1}{q^{n}} \prod_{i=1}^{n}\left[\sum_{t=1}^{q} \rho_{t i}^{2}\right]\right)-\frac{n q}{2} \\
& =-\frac{n q}{2} \ln (2 \pi)-\frac{q}{2} \ln \left(\frac{1}{q^{n}}\right)-\frac{q}{2} \ln \left(\prod_{i=1}^{n}\left[\sum_{t=1}^{q} \rho_{t i}^{2}\right]\right)-\frac{n q}{2} \\
& =\frac{n q}{2}(\ln q-\ln (2 \pi)-1)-\frac{q}{2} \sum_{i=1}^{n} \ln \left(\sum_{t=1}^{q} \rho_{t i}^{2}\right) .
\end{aligned}
$$

The first term in

$$
F(\Theta)=\frac{n q}{2}(\ln q-\ln (2 \pi)-1)-\frac{q}{2} \sum_{i=1}^{n} \ln \left(\sum_{t=1}^{q} \rho_{t i}^{2}\right)
$$

is a constant, and so maximizing $F(\Theta)$ is the same as minimizing the second term. That is, the ML parameter estimates are obtained by minimizing the sum of the logs of the residual sums of squares for each habitat

$$
\operatorname{LRSS}(\Theta)=\sum_{i=1}^{n} \ln \left(\sum_{t=1}^{q} \rho_{t i}^{2}\right)
$$

as a function of the vector $\Theta$ of model parameters. For the models of a single censused habitat $(n=1)$, this is equivalent to minimizing the residual sum of squares

$$
\operatorname{RSS}(\Theta)=\sum_{t=1}^{q} \rho_{t}^{2}
$$

as a function of the vector $\Theta$ of model parameters. The minimizer $\hat{\Theta}$ is the vector of ML parameter estimates for the model. The estimates for the variances are then obtained from the fitted residuals at the ML parameters using equation (5). 
11. Model selection. The goodness-of-fit as measured by $R^{2}$ was used to choose the best model from each suite of competing models. For models of a single censused habitat, $R^{2}$ is given by

$$
R^{2}=1-\frac{\operatorname{RSS}(\hat{\Theta})}{\sum_{t=1}^{q}\left(\sqrt{\text { observation }_{t}}-\text { mean }^{2}\right.},
$$

where mean denotes the mean of the square roots of the observations for the habitat. In the multivariate case there is no standard way of computing an overall $R^{2}$ (Agresti [1990]). In this paper

$$
R^{2}=1-\frac{\sum_{i=1}^{n} \sum_{t=1}^{q} \hat{\rho}_{t i}^{2}}{\sum_{i=1}^{n} \sum_{t=1}^{q}\left(\sqrt{\text { observation }_{t i}}-\operatorname{mean}_{i}\right)^{2}}
$$

was used, where mean $_{i}$ denotes the mean of the square roots of the observations for the $i$ th habitat. The $R^{2}$ estimates the proportion of observed variability explained by the model and thus provides a measure of the accuracy of the model's predictions. The higher the $R^{2}$ value, the better the model fit, with $R^{2}=1$ indicating a perfect fit. Theoretic information criteria such as the Akaike Information Criterion (AIC) were not used since all models within a given suite of competing models had the same number of parameters.

12. Results. The environmental functions that yielded the highest $R^{2}$ values with reasonable parameter estimates for each individual compartmental model are listed in Table 1. Table 1 also lists the ML parameter estimates for the given model structures. Note that many different sets of parameter values may work equally well to give the same $R^{2}$ values.

The four-compartment model derived in this paper accounted for $41 \%$ of the overall variability in the data. The model explained $76 \%$ of the variability in the Pier, and $43 \%$ and $35 \%$ in the Marina and Beach, respectively. Model predictions were of the same magnitude as the observations and typically followed the same general trends represented in the observed data, Figure 3.

Pier predictions and counts showed a steady decline in occupancy in the morning, and a gradual rise in the afternoon (typically around 1100-1200 PST), with the peak toward 2000 hours, Figure 3a. Marina 
counts and predictions, on the other hand, remained fairly constant during most parts of the day, Figure 3b. Occasional large fluctuations in gull numbers in the Marina often corresponded with fluctuations in temperature. An increased occupancy was commonly observed in the Marina at the end of the day; however, the predictions do not show this increase. Beach occupancies fluctuated more than those in the Marina, and showed a general increase in both predicted and observed occupancies toward evening, Figure 3c. There occurred a general decrease in both the observed and predicted occupancies for the 'Other' habitat category toward evening, Figure 3d.

13. Discussion. Short-term fluctuations in habitat occupancies are driven by the functional needs of birds (DeWoskin [1980], Cody [1985], Walsberg [1985]). To carry out various behaviors such as preening, feeding, and resting, gulls need to be located in the appropriate environments (Cooke and Ross [1972]). This leads to diurnal movements among habitats. The flow structures of the various compartmental models are based on combinations of four basic environmental variables: tide, solar elevation, hour of day, and temperature. The results of the model are consistent with the hypothesis that these environmental variables exert a strong influence on the decisions of gulls to move from one habitat to another.

The following discussion focuses on the four-compartment model. Thus, "Other" will henceforth refer to all locations other than the Pier, Marina, and Beach. This includes the nesting area of the colony, the water surrounding Violet Point, and off-island feeding locations.

Per capita flow from the Pier and Beach to Other $\left(r_{41}\right.$ and $\left.r_{43}\right)$, according to the model structure, seems to be driven primarily by a low tide. This is consistent with previous studies that suggest gulls are away from loafing habitats at low tide, probably as a result of increased food availability at low water levels (Patterson [1965], Drent [1967], Galusha and Amlaner [1978], Wondolowski [2002], Henson et al. [2004]). Flow from the Marina to Other $\left(r_{42}\right)$, however, is driven by temperature as well as tide: gulls move from the Marina to Other when temperatures are cool.

Return of the gulls to the Marina and Beach from Other $\left(r_{24}\right.$ and $r_{34}$ ), according to the model, seems to be driven by hour of the day 
A. PIER
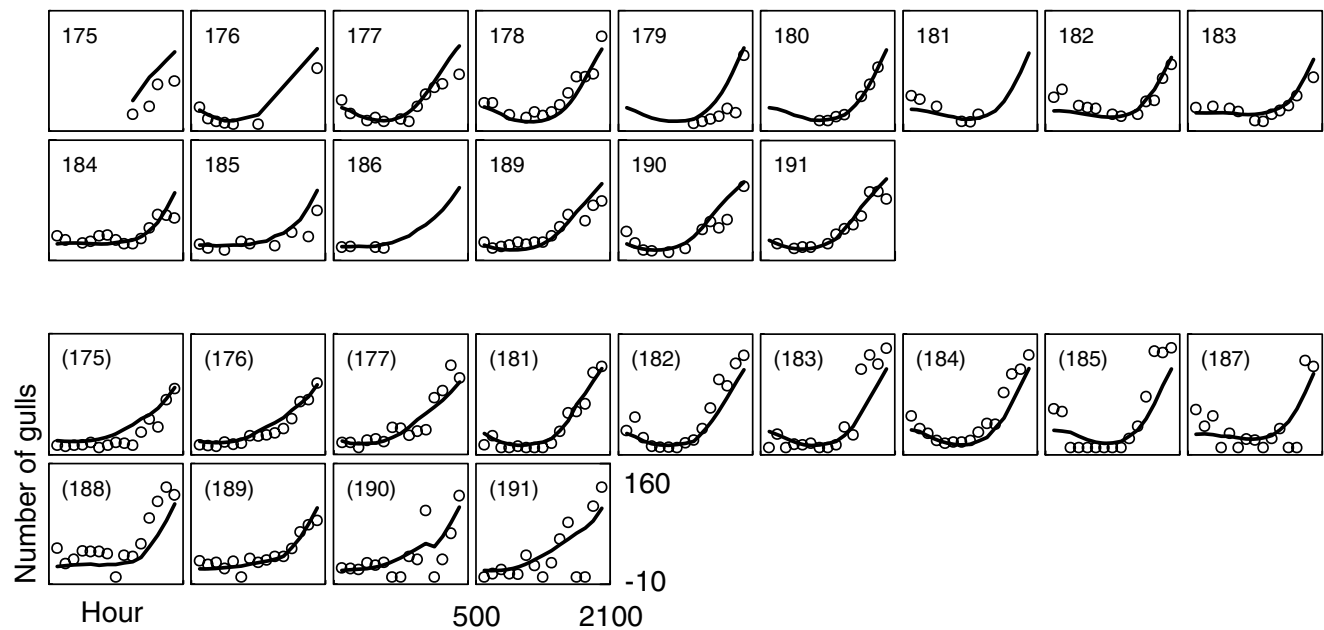

FIGURES 3A-3D. Model predictions versus observations for each of the three gull loafing habitats and "Other" on Protection Island in the four-compartment model. Continuous-time model predictions are plotted as a smooth curve, while open circles are used to plot hourly observations. Each graph shows one day of data, with the day of the year indicated in the upper left-hand corner (without parentheses, 2002; with parentheses, 2003). The horizontal axis is the hour of the day, and the vertical axis is the number of gulls in the habitat. A. Pier, B. Marina, C. Beach and D. Other. Observations and predictions for "Other" were generated by subtracting the sum of the observed and predicted occupancies for the three loafing habitats from K (the total number of gulls in the system). 
B. MARINA
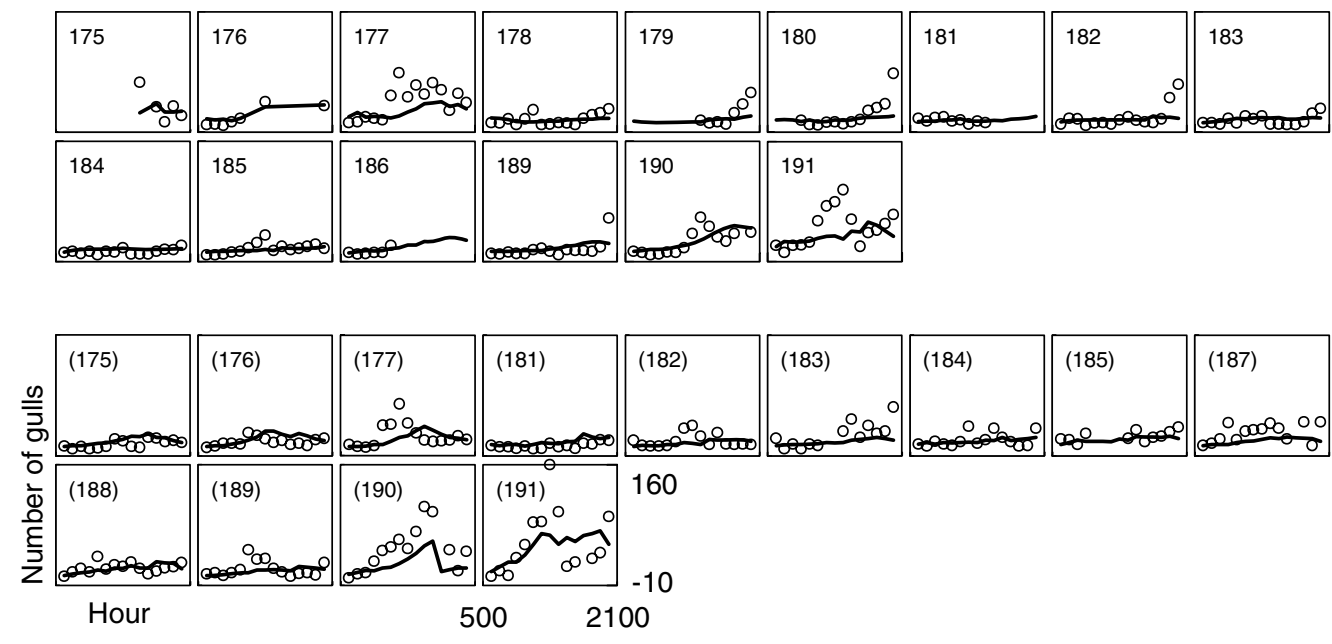

FIGURE 3B. 


\section{BEACH}
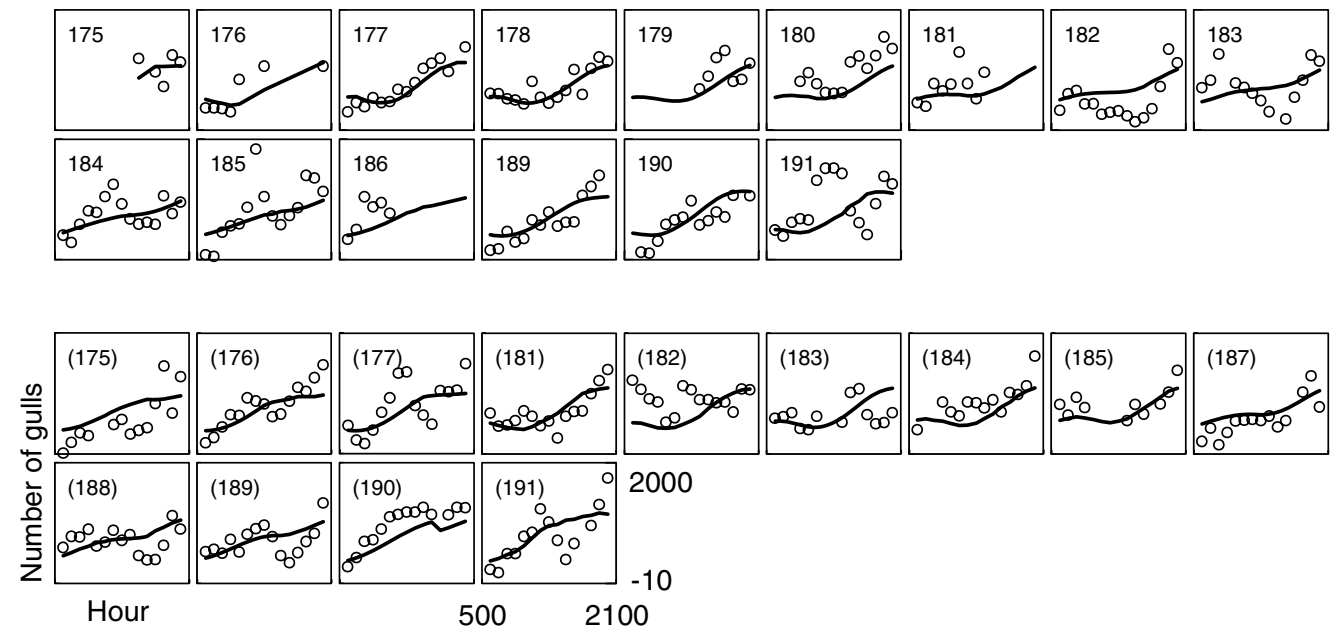

FIGURE 3C 


\section{OTHER}

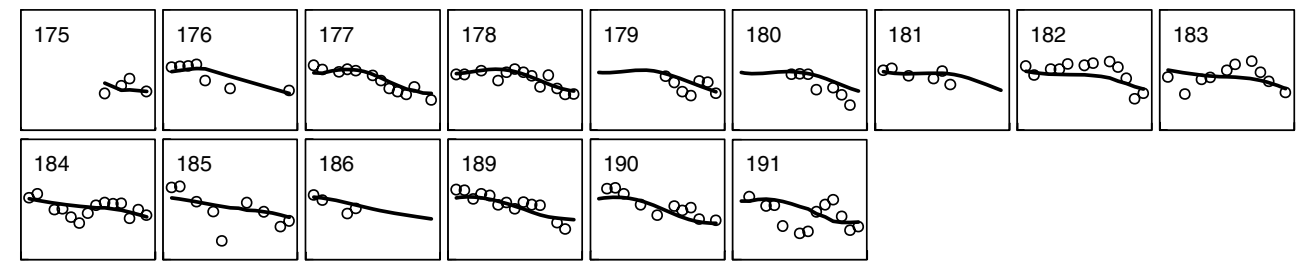

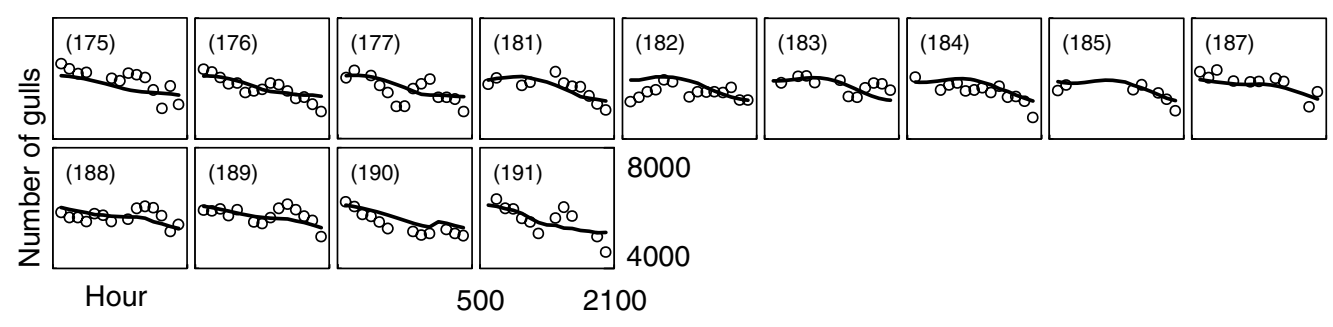

FIGURE 3D 
rather than by high tide. Flow data collected by Phillips [2004] show negligible flow from the nesting colony to the Beach. Thus, flow from Other to the Beach probably originates primarily from the water and off-island feeding locations and presumably consists of gulls returning from feeding. This model structure therefore suggests that the return of gulls to the island from feeding is driven by hour of day rather than tide height and occurs at the end of the day. This is consistent with the increase in observed occupancies at the end of the day.

During data collection, it was observed that birds returning from feeding in off-island locations almost always landed on the beach before dispersing into the other habitats interior to Violet Point. This led to the formulation of the hypothesis that gulls returning from feeding in remote locations land first on the Beach, survey the spit for danger, then move to the nesting colony, and finally disperse to the other habitats (the Pier and the Marina). Even though the four-compartment model structure shows flow from the Other habitat to the Marina, the flow data in Phillips [2004] show that this flow originates primarily from the colony component of Other rather than the off-island locations. This is consistent with the hypothesis that birds returning from feeding land primarily on the Beach. Phillips [2004] showed considerable movement from the Beach to the nesting colony, as opposed to the Pier or the Marina, again agreeing with the hypothesis that gulls returning from feeding, having landed first at the Beach, proceed to the nesting colony before moving to the Pier or Marina habitats.

This model suggests that abundance dynamics in the Marina are driven primarily by temperature. All movements in and out of the Marina, according to this model structure, have a temperature component and seem to be tied to a functional need to cool off during the hot periods of the day. Increases in temperature correspond with increases in flow into the Marina and vice versa. A slight increase in the occupancy in the Marina was typically noted during the middle of the day when ambient temperature is usually at its highest. The relationship between Marina occupancy and temperature was observed most clearly during particularly hot days, such as day 191 in the summer of 2003, Figure 3B. This was the hottest day during the 2003 sampling period, and Marina occupancies were noted to be higher than usual. 
The per capita flow rate from the Marina to the Pier $\left(r_{12}\right)$ in the model is proportional to the ratio hour $/ t_{e m p}{ }^{2}$. Since this fourcompartment model structure eliminates flow from Other to the Pier, the return of gulls to the Pier, presumably from feeding, occurs via the Marina. This is consistent with the increase in Pier occupancies noted at the end of the day.

While the observed data generally matched trends predicted by the model, there existed considerable departure of data from model predictions. This variability may be explained by several factors:

1. Observational error: Count errors can occur due to marginal light conditions or fog.

2. Density dependence: The model assumes that per capita flow rates between habitats occur in direct response to external environmental factors only. It does not take into account density dependent factors such as Allee effects, social facilitation, or crowding.

3. Boats moored to the Pier: Boats were usually moored to the Pier, which increased the local area available to the birds for loafing. Although occupancy counts for the Pier did not include birds loafing on the boats, the presence of boats may have resulted in an underrepresentation of the total number of birds using the Pier habitat.

4. Disturbances: Data collected within $30 \mathrm{~min}$ of an observed disturbance (e.g., Pier being cleaned, boat approaching the Pier, Bald Eagle flying over the island) were discarded for that time period, but unobserved disturbances may have influenced habitat occupancies.

5. Estimation of $K$ : The total number of birds in the system, $K$, was calculated on the basis of the highest value obtained for the sum of the occupancies within all habitats. This method provided the smallest estimation for $K$. The total number of birds in the system may actually have been higher than the $K$ value calculated and used in the model. 
6. Sampling, and model misspecification of Beach: The Pier and Marina yielded higher $R^{2}$ values than the Beach. This may be partly due to the fact that the Beach observations were based on a sample area and then scaled up by a calculated scaling factor. Furthermore, observations of the Beach suggested that behaviors related to nesting, as well as loafing behaviors, occurred on the Beach. The variety of behaviors may have confounded dynamic patterns.

In view of the differential equations developed, there were two possible approaches to predicting the habitat occupancies. One approach was to numerically integrate the differential equations over the past. This approach would have been quite difficult because it necessitates splining environmental data and requires considerable computation time. A second approach, and the one taken here, was to use a priori knowledge (that the system operated on two time scales) to derive algebraic equations for the steady state dynamics of the differential equations. This approach vastly simplified simulation and parameterization. Use of the algebraic models instead of the differential equations meant, however, that the identities of the individual flow rate functions and their parameters could not be determined uniquely from steady state data alone. Thus, one cannot return to the differential equations and predict dynamics on both time scales. Indeed, the very structure of the model determined by this method is by no means unique, and several other model structures may exist which give equally good $R^{2}$ values. While the model in this paper makes biological sense, determination of the true model structure would require data collected immediately after disturbance (Henson et al. [2005]). It is also important to note that the environmental variables identified in this study are correlative with the dynamics, and may or may not be causative.

The model makes use of four environmental variables: tide height, solar elevation, hour of day and temperature. While long-term predictions are possible for the former three environmental variables, temperature in this sense is unpredictable. A long-term predictive model must rely on predictable environmental variables. The use of temperature in this model therefore limits its predictive capability. When temp was replaced with 1 in the four-compartment system, the overall $R^{2}$ of the system after reparameterization dropped from 0.41 to 0.38 . The elimination of temperature from the model resulted in a drop in all $R^{2}$ 
values. The Pier and the Beach $R^{2}$ values dropped very little (from 0.76 and 0.36 to 0.75 and 0.34 , respectively). The Marina $R^{2}$, however, was drastically affected, dropping from the previous 0.43 to 0.13 . This once again emphasizes the strong influence of temperature on Marina occupancy dynamics. Although the use of temperature precludes specific long-range predictions, it facilitates the study of the impact of longterm changes in ambient temperature on abundance and distribution dynamics. This will be addressed in future work.

Three distinctive aspects of the methodology in this study should be emphasized. First, for each system of habitats considered, model selection methods were used to choose the best model from a suite of alternatives. This allowed a reduction in the number of parameters to be estimated, since alternative integer exponents in $E_{i j}=$ tide $^{a_{i j}}$ sun $^{b_{i j}}$ temp $^{c_{i j}}$ hour $^{d_{i j}}$ were treated as alternative hypotheses rather than parameters. Second, a step-wise approach was used in constructing the four-compartment model. By first finding the best flow rate structure for two-compartment and then three-compartment systems, the number of alternative four-compartment models was vastly reduced. Third, the mathematical procedure presented here differs significantly from the usual statistical approach. Statistics-based analyses are useful in that they allow identification of environmental factors correlated with dependent variables. Commonly, however, such analyses entail data averaging, a procedure that can mask informative differences among daily patterns. For resource personnel who make management decisions about marine bird and mammal populations, the mathematical methodology outlined in this study and that of Hayward et al. [2005], in tandem with preliminary statistical exploration, can offer a distinct advantage over purely statistics-based recommendations.

14. Conclusion. This study shows that it is possible to make predictions of diurnal movement and abundance of Glaucous-winged Gulls in a four-compartment system based solely on the strength of the environmental cues that drive movement in and out of a habitat. Despite the nexus of biotic interactions within the system, these birds apparently are heavily influenced by environmental cues in making movement decisions. This dependence is strong enough to allow for the development of mathematical models. 
The simple algebraic approach used in this paper may be applied in the study of movement patterns of other marine birds and animals. An enhanced understanding of how abiotic factors influence the distribution and abundance of organisms is of significant consequence to conservation biologists and natural resource managers. Predictive ecological models allow for testing the impact of environmental policy implementation on ecological systems, thus promoting better resource management.

Acknowledgments. We would like to thank Kevin Ryan and the U.S. Fish and Wildlife Service for their permission to work on Protection Island National Wildlife Refuge; Walla Walla College Marine Station for logistical support; Jim Cushing, Joe Galusha, Tom Goodwin, and Clara Logan for discussions; and all the members of the Seabird Ecology Team at Andrews University for support and suggestions. This research was funded in part by faculty grants from Andrews University and by National Science Foundation grant DMS 0314512.

\section{REFERENCES}

A. Agresti [1990], Categorical Data Analysis, John Wiley \& Sons, Inc., New York.

Anonymous [1998], Evergreen Pacific Tide Guide 1999, Evergreen Pacific Publ. Ltd., Shoreline, WA.

T.G. Benton, C.T. Lapsley and A.P. Beckerman [2002], The Population Response to Environmental Noise: Population Size, Variance and Correlation in an Experimental System, J. Animal Ecol. 71, 320-332.

O.N. Bjørnstad and B.T. Grenfell [2001], Noisy Clockwork: Time Series Analysis of Population Fluctuations in Animals, Science 293, 638-643.

M.L. Cody [1985], An Introduction to Habitat Selection in Birds, in Habitat Selection in Birds (M.L. Cody, ed.), Academic Press, Orlando, FL, pp. 3-56.

F. Cooke and R.K. Ross [1972], Diurnal and Seasonal Activities of a PostBreeding Population of Gulls in Southeastern Ontario, Wilson Bull. 84, 164-172.

R.F. Costantino, J.M. Cushing, B. Dennis and R.A. Desharnais [1995], Experimentally Induced Transitions in the Dynamic Behavior of Insect Populations, Nature 375, 227-230.

R.F. Costantino, R.A. Desharnais, J.M. Cushing and B. Dennis [1997], Chaotic Dynamics in an Insect Population, Science 275, 389-391.

B. Dennis, R.A. Desharnais, J.M. Cushing, S.M. Henson and R.F. Costantino [2001], Estimating Chaos and Complex Dynamics in an Insect Population, Ecol. Monographs 71, pp. 277-303. 
R. DeWoskin [1980], Heat Exchange Influence on Foraging Behavior in Zonotrichia Flocks, Ecology 61, 30-36.

R.H. Drent [1967], Functional Aspects of Incubation in the Herring Gull (Larus argentatus Pont.), Behaviour Suppl. 17, 1-32.

J.G. Galusha and C.J. Amlaner [1978], The Effects of Diurnal and Tidal Periodicities in the Numbers and Activities of Herring Gulls Larus argentatus in a Colony, Ibis 120, 322-328.

G.F. Fussmann, S.P. Ellner, K.W. Shertzer and N.G. Hairston [2000], Crossing the Hopf Bifurcation in a Live Predator-Prey System, Science 290, 1358-1360.

J.L. Hayward, S.M. Henson, C.J. Logan, C.R. Parris, M.W. Meyer and B. Dennis [2005], Predicting Numbers of Hauled-Out Harbour Seals: A Mathematical Model, J. Appl. Ecol. 42, 108-117.

S.M. Henson, R.F. Costantino, J.M. Cushing, R.A. Desharnais, B. Dennis and A.A. King [2001], Lattice Effects Observed in Chaotic Dynamics of Experimental Populations, Science 294, 602-605.

S.M. Henson, J.L. Hayward, C.M. Burden, C.J. Logan and J.G. Galusha [2004], Predicting Dynamics of Aggregate Loafing Behavior in Glaucous-Winged Gulls (Larus glaucescens) at a Washington Colony, Auk 121, 380-390.

S.M. Henson, J.L. Hayward and S.P. Damania [2005], Identifying Environmental Determinants of Diurnal Distribution in Marine Birds and Mammals, Bull. Math. Biol., to appear.

R.V. Hogg and A.T. Craig [1978], Introduction to Mathematical Statistics, 4th ed., Macmillan, New York.

F.C. Hoppensteadt [1975], Mathematical Theories of Populations: Demographics, Genetics and Epidemics, Reg. Conf. Ser. in Appl. Math., Vol. 20, SIAM, Philadelphia, PA.

I.J. Patterson [1965], Timing and Spacing of Broods in the Black-Headed Gull Larus ridibundus L., Ibis 107, 433-459.

K.W. Phillips [2004], Habitat Patch Occupancy Dynamics of Glaucous-Winged Gulls (Larus glaucescens): A discrete-time model, M.S. Thesis, Andrews University, Berrien Springs, MI.

K.W. Phillips, S.P. Damania, J.L. Hayward, S.M. Henson and C.J. Logan [2005], Habitat Patch Occupancy Dynamics in Glaucous-Winged Gulls (Larus glaucescens) I: A Discrete-Time Model, Natur. Resource Modeling 18, 441-468.

C.R. Rao [1973], Linear Statistical Inference and Its Applications, 2nd ed., John Wiley \& Sons, New York.

E.D. Silverman and M. Kot [2000], Rate Estimation for a Simple Movement Model, Bull. Math. Biol. 62, 351-375.

E.D. Silverman, M. Kot and E. Thompson [2001], Testing a Simple Stochastic Model for the Dynamics of Waterfowl Aggregations, Oecologia 128, 608-617.

A.N. Tikhonov, A.B. Vasil'eva and A.G. Sveshnikov [1985], Differential Equations, Springer, Berlin. 
G.E. Walsberg [1985], Physiological Consequences of Microhabitat Selection, in Habitat Selection in Birds (M.L. Cody, ed.), Academic Press, Orlando, FL, pp. 389-413.

L. Wondolowski [2002], Diurnal Activity Patterns of Wintering Gulls at Jug Bay Wetland Sanctuary, M.S. Thesis, Bard College, Annendale-on-Hudson, NY. 